\title{
ANL/APS/PP. - - i.5/62
}

\section{A Soft X-Ray Undulator for the U5 Beamline at NSLS*}

P. J. Viccaro, G. K. Shenoy and S. H. Kim

Advanced Photon Source, Argonne National Laboratory, Argonne, IL 60439

and

S. D. Bader

Materials Science Division, Argonne National Laboratory, Argonne, IL 60439

\section{DISCLAIMER}

This report was prepared as an account of work sponsored by an agency of the United States Government. Neither the United States Government nor any agency thereof, nor any of their employees, makes any warranty, express or implied, or assumes any legal liability or responsibility for the accuracy, completeness, or usefulness of any information, apparatus, product, or process disclosed, or represents that its use would not infringe privately owned rights. Reference herein to any specific commercial product, process, or service by trade name, trademark, manufacturer, or otherwise does not necessarily constitute or imply its endorsement, recommendation, or favoring by the United States Government or any agency thereof. The views and opinions of authors expressed herein do not necessarily state or reflect those of the United States Government or any agency thereof.

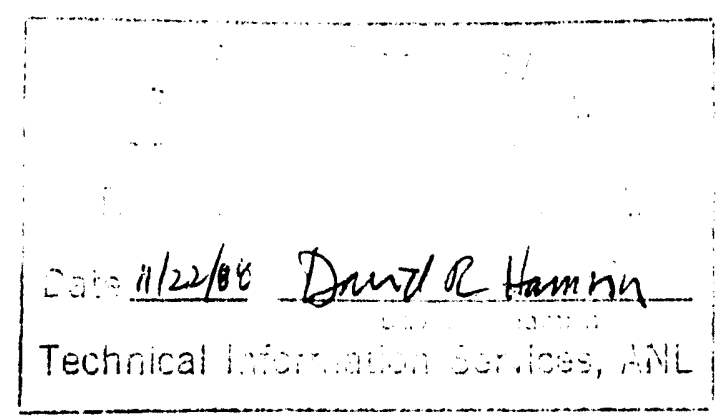

\footnotetext{
*This work supported by the U.S. Department of Energy, BES-Materials Sciences, under contract no. W-31-109-ENG-38. 


\section{A Soft $X$-Ray Undulator for the U5 Beamline at NSLS*}

P. J. Viccaro, G. K. Shenoy and S. H. Kim

Advanced Photon Source, Argonne National Laboratory, Argonne, IL 60439 USA and

S. D. Bader

Materials Science Division, Argonne National Laboratory, Argonne, IL 60439

\section{Abstract}

The magnetic structure and spectral properties of a $7.5-\mathrm{cm}, 30-$ period hybrid undulator are described. The device will be installed at the U5 port of the VUV storge ring at Brookhaven National Laboratory and will be a tunable source of very high brillance soft $x$-ray radiation over the range of 13 from approximately $150 \mathrm{eV}$.

*This work supported by the U.S. Department of Energy, BES-Materials Soiences, under contract no. W-31-109-ENG-38. 


\section{Introduition}

A tunable hybrid undulator to be installed at the $U 5$ port of the VUV $r$ ing at the National Synchrolron Light Source (NSLS) is in the final stages of its design. Construction of the device is expected to be completed by the end of early 1989. The undulator will cover the spectral range from approximately 13 to $150 \mathrm{eV}$ using the first and third harmonic radiation and will be a high brightness source of soft $x$-rays.

The unique spectral characteristics of this undulator source in terms of its tunability, intensity and lemporal structure will provide excellent research opportunities in a variety of areas. These include spin-polarized photoelectron spectroscopy of novel magnetic surfaces, molecular photophysics of shape and autoionizing resonances, and time-resolved spectroscopic and scattering studies to monitor surface chemical reactions and interface phe nomona.

In the following, some aspects of the design of the magnetic structure of the undulator are presented as well as results of calculations of the expected spectral properties which explicitly include the emittance properties of the VUV storage ring.

\section{Magnetic Design}

The transverse undulator has a hybrid magnet configuration in which the field quality is much less dependent on the manufacturing tolerances of the permanent magnet materials than in Halbach's original pure REC design. ${ }^{1}$ The device uses $\mathrm{Nd}-\mathrm{Fe}-\mathrm{B}$ magnets and vanadium permendur pole tips. The design is based on an optimization procedure in which the geometrical parameters of the structure are varied in two-dimensional (PANDIRA ${ }^{2}$ ) and three-dimensional ${ }^{3}$ field computations. The resulting parameters are presented in Table 1. 
Three-dimensional effects are estimated in order to obtain the pole and magnet width and overhang necessary to obtain the required horizontal field homogeneity and to reduce flux loss. 4

TABLE 1

Magnetic Specifications of the U5 Hybrid Undulator

$\begin{array}{ll}\text { Total Length }(\mathrm{m}) & 2.25 \\ \text { Period Length (cm) } & 7.5 \\ \text { Magnet Materiai } & \text { Nd-Fe-B } \\ \text { Coercive Force (kOe) } & \geq 10.6 \\ \text { Pole Material } & \text { Vanadium Permendur } \\ \text { Minimum Gap (cm) } & 3.4 \\ \text { Peak Field }(\mathrm{T}) & 0.42 \\ \text { Pole Width (cm) } & >7.5 \\ \text { Pole Overhang (mm) } & 1 \\ \text { Magnet Width (cm) } & \geq 10.7 \\ \Delta B_{r m s} \text { B } & <0.01 \text { on centerline } \\ \text { Harmonic Content } & <2 \% \\ \text { of Field } & \\ \text { Residual Steering } & \geq 100 \mathrm{G}-\mathrm{cm} \text { vertical } \\ \text { Errors } & \geq 100 \mathrm{G} / \mathrm{cm} \\ \text { Sextupole Error } & 0.008 \text { on centerline } \\ \text { Phase Error }(\Delta \lambda / \lambda) & \end{array}$

Figure 1 shows a two-dimensional cross section of the upper half of the magnetic structure including the end-pole configuration. Also shown are the magnetic flux lines from the PANDIRA calculations at the minimum gap of 3.4 $\mathrm{cm}$. The pole overhang in the vertical (y) direction is $1 \mathrm{~mm}$ and the pole thickness is $1.40 \mathrm{~cm}$. The magnet overhang in the horizontal $(x)$ direction is $1.5 \mathrm{~cm}$, which minimizes the field roll-off and reduces flux losses in this direction.

The estimated peak-field value of $0.42 \mathrm{~T}$ at the closed-gap setting assumes a coercive force for the $\mathrm{Nd}-\mathrm{Fe}-\mathrm{B}$ of $-10.6 \mathrm{kOe}$ and also a finite magnet width. The expected harmonic content of $<2 \%$ (see Table 1 ) in the field along the longitudinal direction is determined primarily by the pole thickness ( 1.4 $\mathrm{cm}$ ) compared to magnet thickness. 
For the hybrid geometry, the field has an approximate exponential-like dependence on the gap and, therefore, $K$ and consequently $E_{j}$ are functions of the gap. For the minimum gap of $3.4 \mathrm{~cm}$ and a $\mathrm{ring}$ energy of $0.75 \mathrm{GeV}$, the fundamental occurs at approximately $13 \mathrm{eV}$ with a K-value of 2.9. At the open gap position, with $K=1$, the fundamental occurs at approximately $50 \mathrm{eV}$. With these $\mathrm{K}$-values, excellent spectral intensity will be available at the third harmonic and consequently, the combined fundamental and third harmonic tunability range will be 13 to approximately $150 \mathrm{eV}$.

The actual spectral intensity as a function of $x$-ray energy has been calculated using a Monte Carlo numerical code which take the electron beam emittance into account. The VUV-ring parameters used are given in Table 2. Figure 3 show the on-axis spectral brilliance of the device in $\left(\mathrm{ph} / \mathrm{s} / 0.1 \% \mathrm{BW} / \mathrm{mrad}^{2} \mathrm{~mm}^{2}\right)$ as a function of photon energy for the minimum gap with $K=3$ and the open gap of approximately $6 \mathrm{~cm}$ where $K=1$. At $r$ ing currents of $750 \mathrm{~mA}$, a spectral brilliance above $10^{16}$ is expected at the harmonics over the tunability range. Quite sizable second on-axis harmonic radiation is also observed at all the gap settings due to the finite size and divergence of the electron beam.

TABLE 2

Electron beam parameters for the VUV ring used in the calculation of the spectral properties

Ring Energy

Stored Current Horizontal Emittance

Vertical Emittance Horizontal Betatron Function Vertical Beatatron Function
$0.750 \mathrm{GeV}$

$750 \mathrm{~mA}$

$90 \mathrm{~nm}-\mathrm{rad}$

$0.9 \mathrm{~nm}-\mathrm{rad}$

$11.6 \mathrm{~m}$

$5.5 \mathrm{~m}$ 
The spectral brilliance for the fundamental and third harmonic is shown in Fig. 4 over the tunability range expected for the device. These results indicate that high brilliance (and hence spectral intensity) exceeding $10^{16}$ $\mathrm{ph} / \mathrm{s} / 0.1 \% \mathrm{BWmrad}^{2} \mathrm{~mm}^{2}$ can be achieved over the tunable photon energy range of 13 to $150 \mathrm{eV}$. This represents a usable tunability interval which is a factor of ten times the minimum fundamental energy possible.

At the odd harmonic energies, the spatial distribution of the radiation for the case of zero particle beam emittance consists of a central intense radiation cone surrounded by rings of weaker intensity. The anglular width of the central cone is given by $V(\lambda / L)$ where $\lambda$ is the $x$-ray energy and $L$, the undulator length. 6 For the upoer and lower gap settings, this corresponds to 0.6 and $2 \mathrm{mrad}$, respectively, for the fundamental. The angular divergence due to the finite particle beam emittance is approximately 0.1 and $0.6 \mathrm{mrad}$ in the horizontal and vertical directions, respectively. Consequently, the effective width of the central cone is dominated by the radiative width except for the closed-gap fundamental in the horizontal direction.

Calculation of the photon flux through a $0.14 \mathrm{mrad} \times 0.14 \mathrm{mrad}$ pin-hole expected over the spectra range for the two gap settings is given in Fig. 5 . The calculations show that at a harmonic, x-ray fluxes of greater than $10^{13}$ $\mathrm{ph} / \mathrm{s} / 0.1 \% \mathrm{BW}$ can be expected. This is approximately 100 times larger than that achieved on a bending magnet beamline at the VUV ring with the same pin-hole size.

4. Conclusions

The magnetic design of the variable-gap tunable undulator to be installed on the VUV-ring at the National Synchrotron Light Source is in its final stages, and construction of the device should begin soon. The magnetic properties have been optimized to provide enhanced spectral brilliance over a 
large tunability range which is ten times the energy of the fundamental at the closed gap position. The large flux expected for the device over the soft $x$-ray range will provide new possibilities for experiments in the areas of spin-polarized photoemission, surface science and materials science.

\section{Acknowledgement}

This work was supported by the U.S. Department of Energy, BES-Materials Sciences, under contract No. W-31-109-ENG=38. The undulator development project at NSLS is supported by the ONR under Contract No. N00014-87-F-0022. 


\section{References}

1. K. Halbach, Journal de Physique 44, C1-211 (1983).

2. PANDIRA is an improved version of POISSON which allows solution of permanent magnet and residual error problems. POISSON is a version of TRIM developed by $K$. Halbach.

3. S. H. Kim, IEEE Trans. On Magnetics, Vol. 24, 1102 (1988).

4. K. Halbach, E. Hoyer, S. Marks, D. Plate and D. Shuman, IEEE Trans. on Nucl. Science, NS-32, 3640 (1985).

5. See, for example, S. Krinsky, M. L. Perlman and R. F. Watson in Handbook on Synchrotron Radiation, Vol. 1a, ed by E. E. Koch, North Holland, 1983, p. 65 .

6. K.-J. Kim, Nucl. Inst. Meth. A246, 71 (1986). 
Eigure Caption

Fig. 1 Horizontal ( $x$ ) cross section of the upper half of the undulator magnet structure including the end-pole configuration. The flux lines are from a PANDIRA calculation at the minimum gap of $3.4 \mathrm{~cm}$. Here $M$ is $N d-F e-B$ magnet and $P$ is vanadium permendur pole. $H_{M}$ and $T_{M}$ are the magnet height and thickness and $H_{p}$ and $T_{p}$, the pole height and thickness, respectively.

Fig. 2 Plot of the vertical (y) component of the mid-plane on-axis flux of the undulator near the end pole region at the minimum gap.

Fig. 3 On the on-axis spectral brilliance of the U5 undulator including emittance effects of the VUV ring, at the open $(K=1 \mathrm{~cm})$ and closed gap $(K=3)$ positions.

Fig. 4 The spectral brilliance of the fundamental and third harmonic over the entire tunability range.

Fig. 5 The flux through a $0.14 \mathrm{mrad}$ by $0.14 \mathrm{mrad}$ pinhole on axis as a function of photon energy at the open $(K=1)$ and closed $(K=3)$ gap positions. 


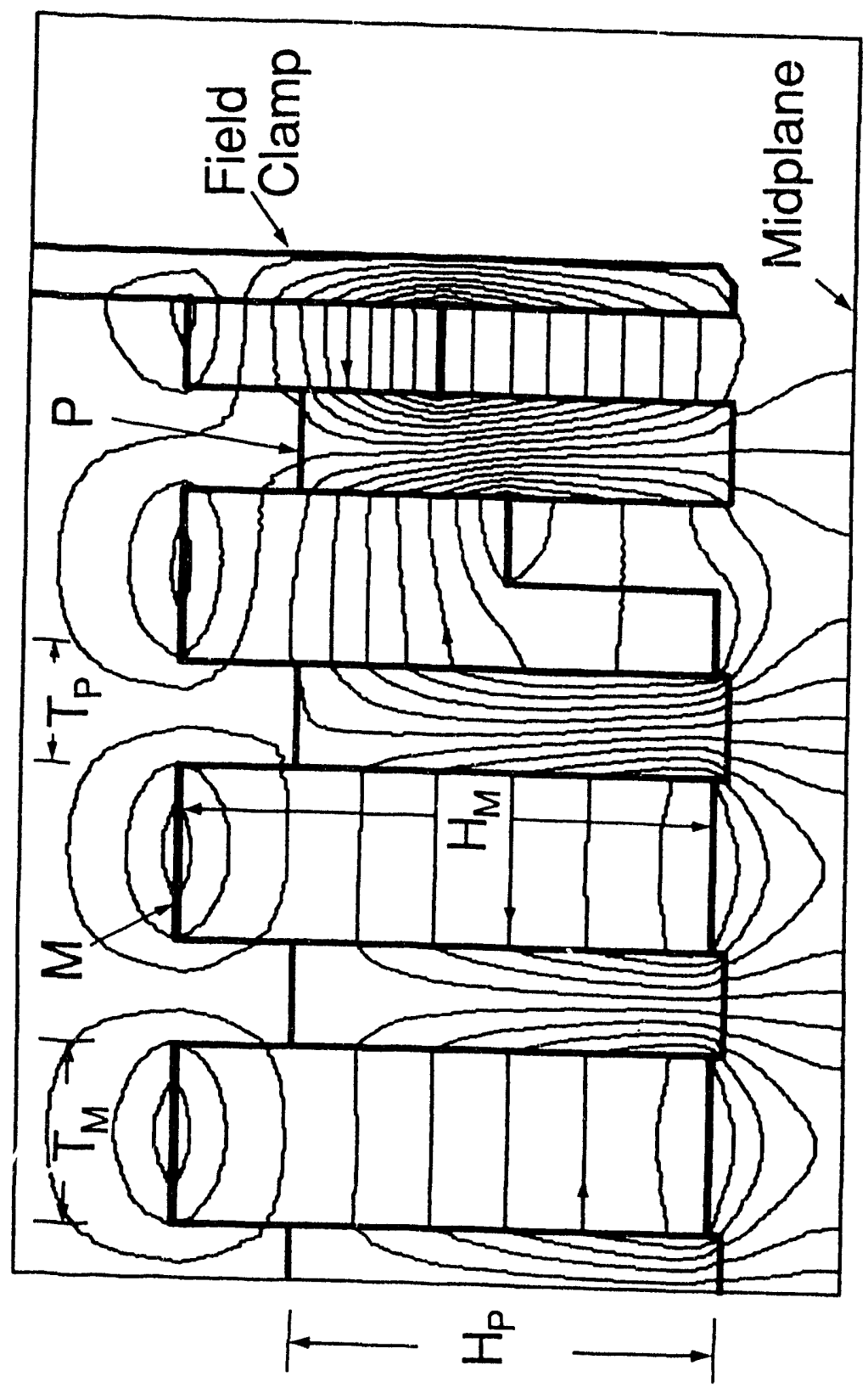




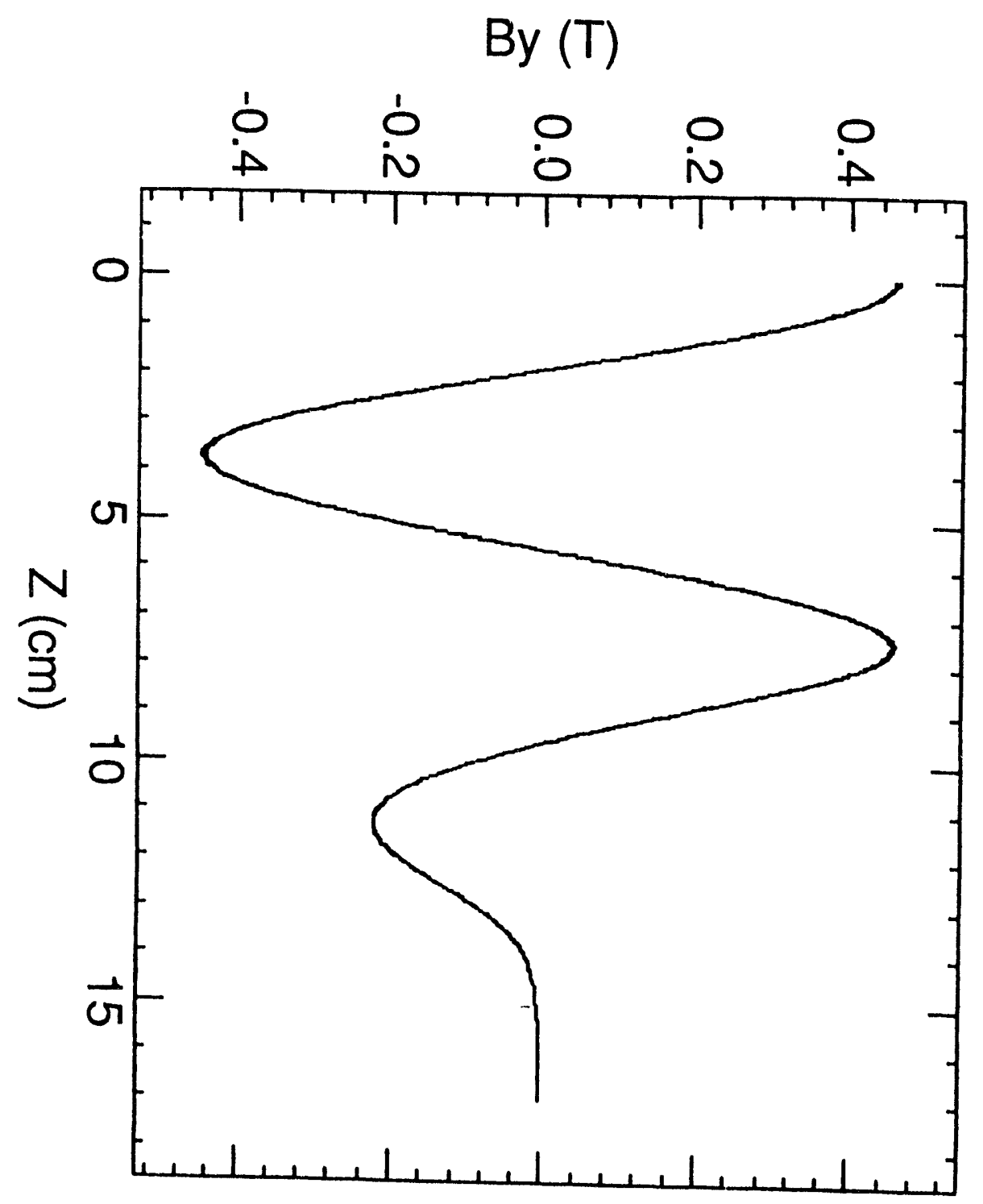




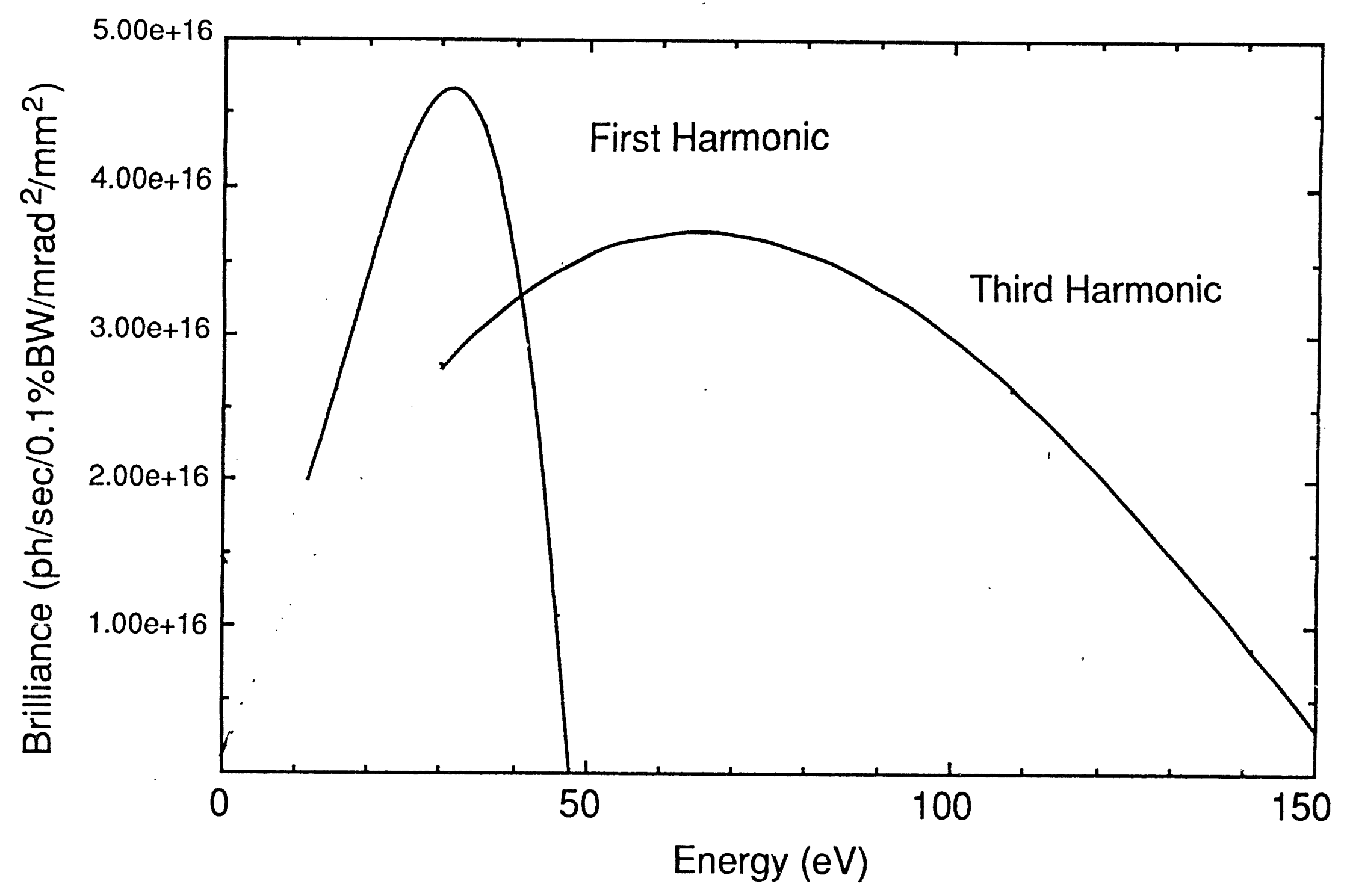




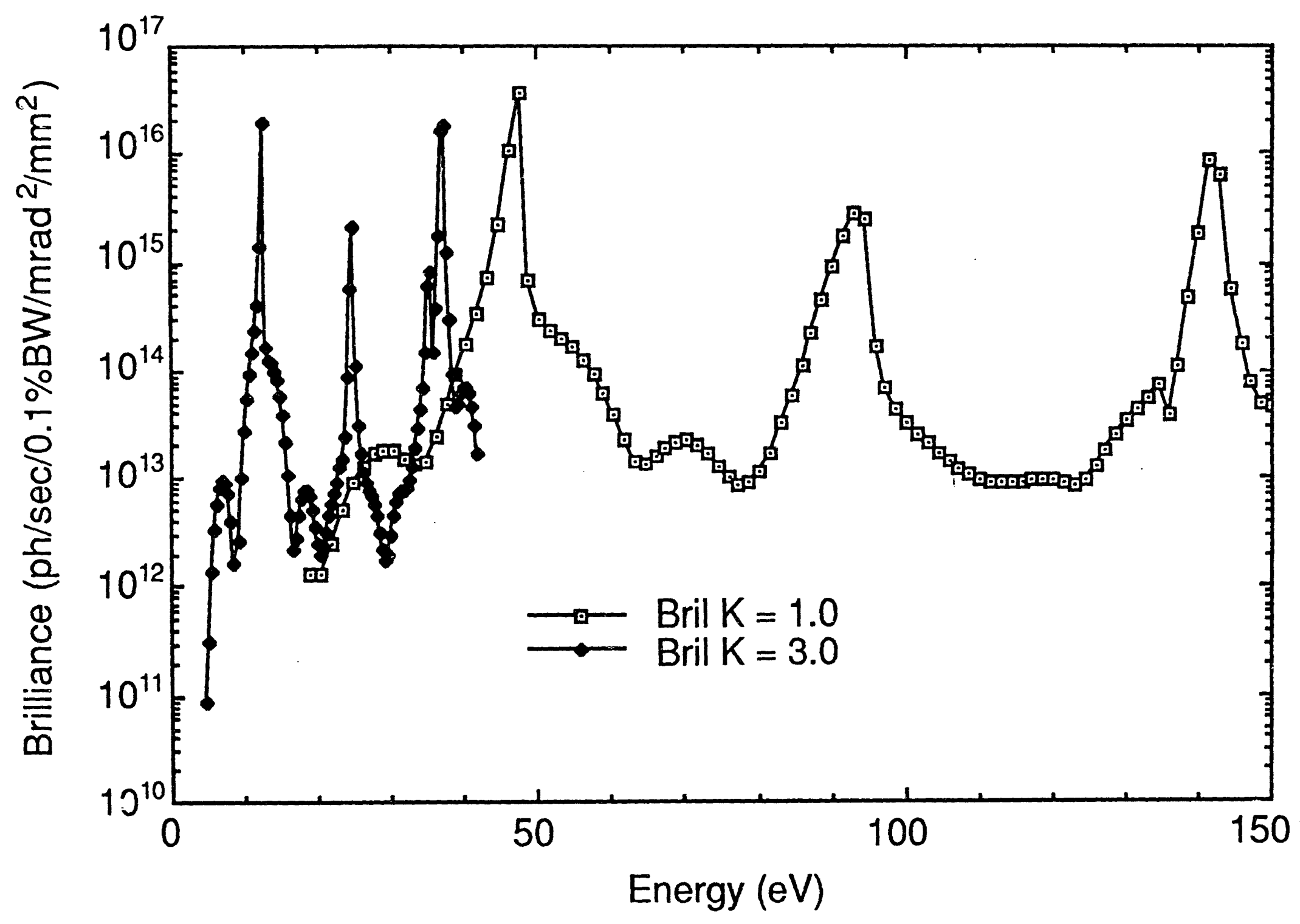




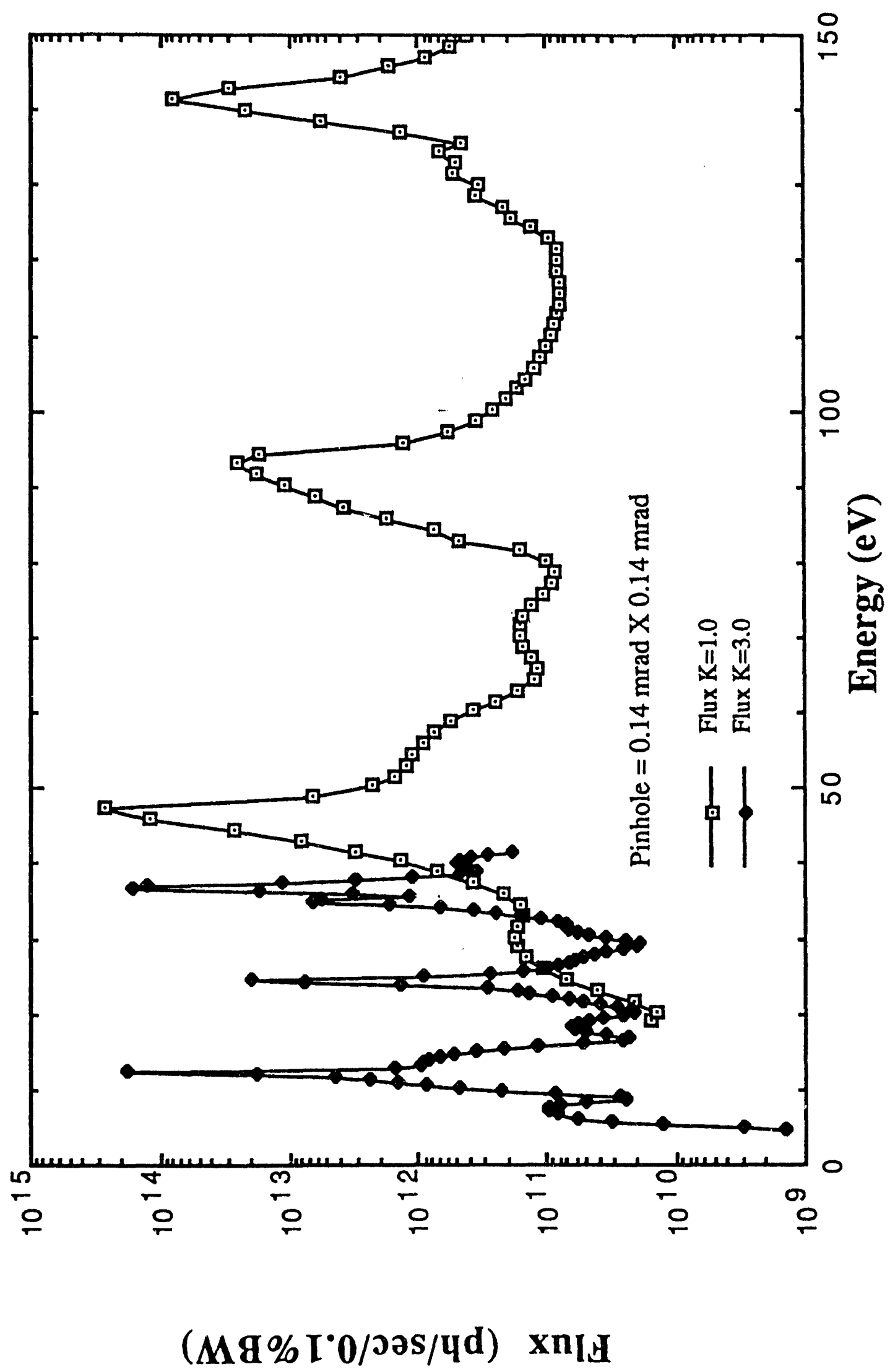



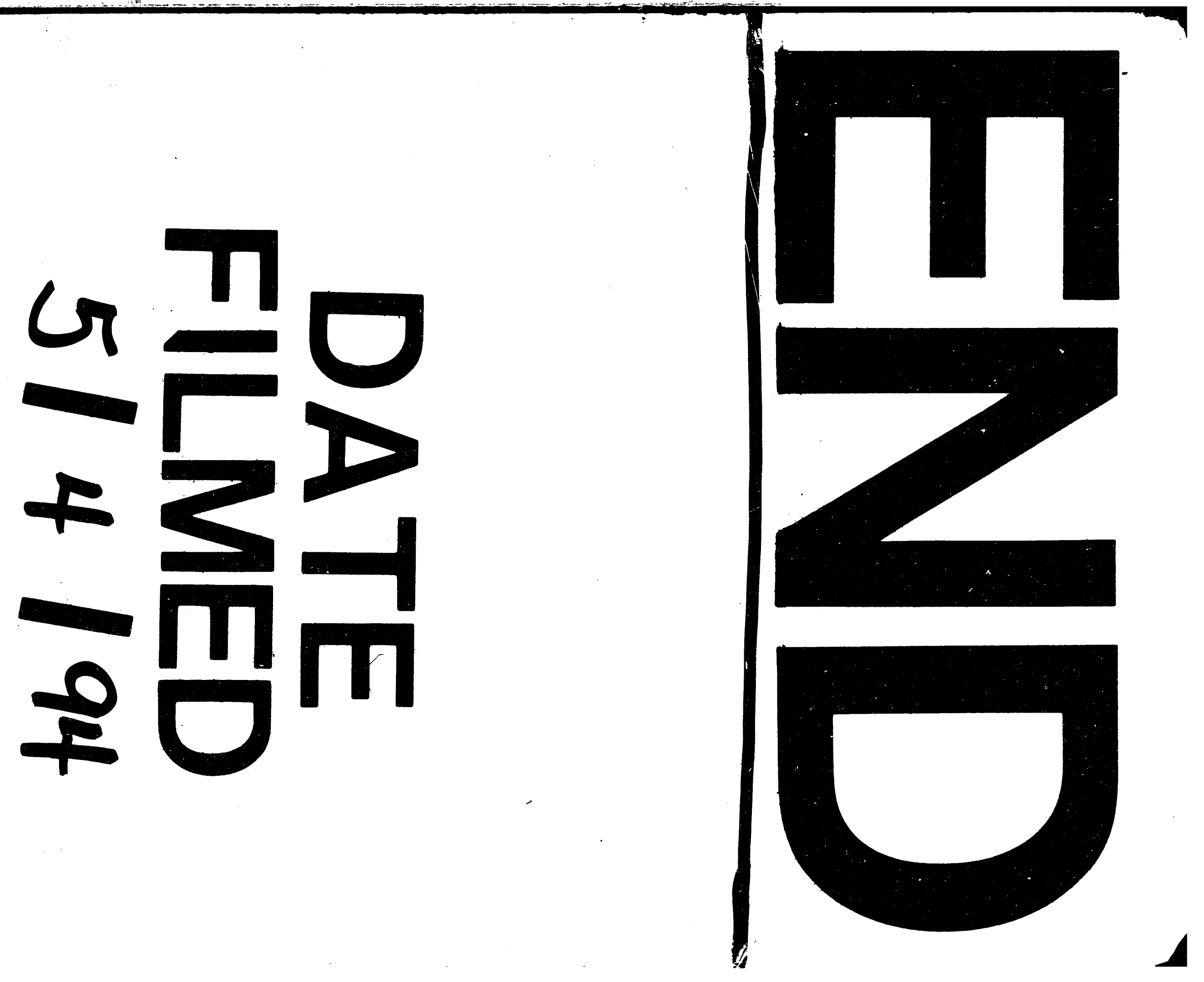
